time she is well enough to perform all the ordinary duties of her station.

In this brief record of (what was to $m e$ ) a most interesting case, I have designedly omitted many details, as not bearing directly upon the object $I$ have had in view in reporting it. It is evident that the application of cold to the body in cases where the temperature of the blood rises to a pitch at which it imperils the action of the heart (threatens its paralysis in fact), is as justifiable a course in rheumatic fever as in any other.

Old Trafford, Manchester.

\section{TWO CASES OF THORACIC ANEURISM.}

\section{BY FREDERICK ENSOR, M.R.C.S.,}

SURGHON TO THE PROVINOIAL HOSPITAL, PORT BLIZABHTH, SOUTH APRICA.

To the physician who is alive to the insidious nature of thoracic aneurism, no cases cause more anxiety than those which exbibit symptoms of this grave organic lesion. I imagine in every hospital of seaport towns "cases" from the shipping are admitted which of ten puzzle the keenest and most painstaking observer. Men who are dissatisfied with their ship or captain, or who are attracted by diamondfields or stories from gold-fields, will try every ruse to keep in hospital, but directly the vessel is out of sight their recovery is marvellously quick. When a man tells the usniil tale of having pains here and there, and at the same time his pulse and temperature are fairly normal, or perhaps the former a little quickened by his "intent to deceive," and there be no marked symptoms of rheumatism, or expression of malaria or syphilis, you cannot but suspect him of malingrring; and yet he may be the subject of grave internal mischief, causing immediate danger to life. I always like to give a man the benefit of the donbt, and watch and wait for a few days rather than act on a diagnosis which one may have cause to regret.

From manuscript noles of a clinical lecture on a case of aneurism of the aorta, by Dr. Todd, in 1855, I copy the following: "When patients above the age of thirty come to consult you about pains extending over the shoulders and chest, an aneurism should always be suspected." All King's men who had the good fortune to study disease at the bedside under that master in diagnosis, Dr. Todd, will coincide with me that it was a privilege and a treat to see him grapple with a difficult case of heart disease or aneurism: the repeated careful examination; the appreciation of, to us students, trifling symptoms; the patient watching of the man as he perhaps sat on his bedside; and the feeling that the vim, or vital force, or mind, as his disciple, Dr. Brale, would say, was stirring the depth and breadth of bis "cerebral bioplasm," as it strove to solve the "enigma of life" in question, had a good effect on the class, and I dare say bas made not a few strive to follow in the steps of so great a teacher.

The aid to diagnosis, which I quote from the clinical lecture, has been well illustrated in two cases which have come under my observation in this hospital; one occurred some two year's ago, the other a few days since. As necessity of care in diagnosis is the only point I wish to lay stress on in these cases, I will not enter into much detail.

The first case was that of a sailor-I write from memory. He was a tall man, rather thin, aged about forty, and was admitted complaining of pain, not very severe, of a neuralgic character, in the spine and about the chest. The captain "thought he was echeming." He had been under medical treatment for same symptoms; no diagnosis had been distinctly given; he was suspected of trying to get rid of his ship.

I examined him several times and got at no positive symptoms to guide me, and yet there was something in his look which told of suffering, and made one feel that the man's pains were not imaginary. He had been in hospital about a week when I detected a prolonged sound, not amountiug to a " bruit," at the back, between the shoulders. I gave a guarded diagnosis of aneurism of the thoracic aorta. A few days after, in the act of lighting his pipe, he fell dead at his bedside, and the post-mortem examination disclosed a circumscribed aneurism of the descending aorta, which, having eroded two or three of the vertebræ bad given way and filled the left pleura with blood. When men are admitted who, without a doubt, are "sea lawyers," I generally order a few doses of sulphate of magnesia, flavoured with tincture of assafoetida, and I find that they soon ask permission to leave the house. In the post-mortem room I felt glad I had not ordered the "stimulant mixture," as we term it, in the above case.

The second case, which occurred a few days ago, was the following :-A tall, thin, big-boned man, formerly a private in the German Legion, was admitted complaining of pain lancinating in the line of the intercostal nerves and lower part of the chest. No murmur at base or aper of the heart. Pulse even in both radials; no dulness over the middle of the sternum ; no marked dyspnoea. The only thing I could detect was a limited dulness about the middle of the left lung, with rather harsh respiratory sounds; no cough or expectoration; pulse and temperature normal. The man was, nevertheless, conscious of something serious the matter with him; his eyes 'were particularly bright, the sclerotic pearly and clear.

At first I thought he was a dyspeptic "loafer" trying to remain in hospital. A thought of tubercle being laid down crossed my mind, but the pulse and temperature were against this idea. I remarked to the house-surgeon, " that it was not improbable we should find an aneurism in this case." After a careful examination, 1 could come to no conclusion, refused to commit myself to a diagnosis, and simply ordered him to remain in bed. No medicine was prescribed.

Two days after this, while engaged in an operation for crushed foot, the nurse entered the room, saying the German was "in a fit," as she called it. As soon as the operation was completed, on proceeding to the ward, I saw the poor fellow lying in bed, quite dead, with extreme pallor on his face. He had evidently died in a faint. The following day a post-mortem examination revealed an aneurism about the size of a turkey's egg in the descending aorta, which had eroded the seventh and eighth vertebræ, and had burst, filling the pleura with blood. The heart was small, and thin and pale in its muscular structure. The aortic valves were somewhat thickened, but not incomplete; the mitral valve was also thickened a little, but, I imagine, had been equal to its office, or we should have had more dyspnœa. Both lungs were byperæmic, the left slightly consolidated at its contact with the aneurism.

These two cases illustrate well how cantions one should be in coming to a conclusion in a case. A harsh judgment, a wrong diagnosis followed by harmful treatment, would always be a matter of extreme regret to the physician, and, in some cases, might give rise to much social distress. Better that a scheming patient should impose on his doctor for a few days than that a poor fellow with thoracic aneuriam should be hurried to his end by active treatment on a wrong diagnosis.

In Trousseau's "Clinical Medicine," vol. i., p. 597, is a case well illustrating the point $I$ wish to impress in these few remarks.

\section{DIABETES MELLITUS OR GLYCOH AMIA. \\ CASE OF}

Bx SuRgeon JOHN C. LUCAS,

F.M. BOMBAT ARMY; IN MEDTCAL CHARGE H.M. 18TH REGIMTKT, N.I., CAMP DEHSA.

Private Punchum lalla, aged forky; service twenty years; married, but no family. The patient, a man of average height and fair intelligence, says that he enjoyed excellent health until about eighteen months ago, when, serving with the regiment at Rajcote, after repeated attacks of fever and ague, he observed that he began to pass large quantities of urine, and that the calls to micturition had been increasing in frequency, and also thirst had been in proportion excessive. His appetite has been gradually augmenting, and now he describes it to be ravenous. He has been rapidly losing flesh; from being a strong, muscular man, he is reduced almost to a skeleton. He complains of dimness of vision and near-sightedness, which he says have been steadily advancing. He admits having contracted a 